\title{
O PROFESSOR DE ESTUDOS AMAZÔNICOS: O PERCEBER ENTRE O ESPAÇO PENSADO E O ESPAÇO VIVIDO
}

\section{The Amazon Study Teacher: \\ The perception between the thought space and the lived space}

Gabriel Renan Neves Barros Instituto Federal de Educação Ciência e Tecnologia do Pará: Belém, PA gabriel.barros@ifpa.edu.br

Alan Bizerra Martins Universidade Federal do Sul e Sudeste do Pará,PA alanmartinsgeo14@gmail.com

Artigo enviado para publicação em 01/03/2020 e aceito em 19/04/2020

DOI: $10.12957 /$ tamoios.2020.48797

\section{Resumo}

Este artigo trata-se de um capítulo da dissertação de mestrado sobre a formação de professores de Estudos Amazônicos no município de Marabá-PA. Buscamos fundamentar a criação da disciplina a nível municipal, o por que estudar a Amazônia, além de entender qual a relação entre o perceber e o ato de ensinar, o perceber e o professor, assim como o perceber e o aluno. Neste artigo é possível entender, através de Merleau-Ponty, Masini, Paulo Freire, Vygotsky, Gomes, Milton Santos e outros, qual a participação dos sujeitos no mundo, mais especificamente, no meio ambiente amazônico, e sua importância para a construção de uma consciência coletiva preservacionista.

Palavras-Chave: Estudos Amazônicos; Formação; Perceber; Espaço vivido; Consciência Coletiva.

\begin{abstract}
This article deals with a chapter of the master's thesis on the formation of teachers of Amazonian Studies in the municipality of Marabá-PA. The buses underpin the creation of the discipline at the municipal level, or what you study in the Amazon, in addition to understanding what is the relationship between perception and the act of practicing, perception and the teacher, as well as perception and the student. In this article it is possible to understand, through Merleau-Ponty, Masini, Paulo Freire, Vygotsky, Gomes, Milton Santos and others, to qualify the participation of individuals in the world, more specifically, the Amazonian environment and its importance for the construction of a preservationist collective consciousness.
\end{abstract}

Keywords: Amazonian Studies; Formation; To perceive; Lived space; Collective Awareness. 


\section{Introdução}

No estado do Pará está inclusa a disciplina Estudos Amazônicos de $6^{\circ}$ ao $9^{\circ}$ ano do Ensino Fundamental. Essa inclusão é normatizada por legislação federal, estadual e municipal, como exemplo podemos citar a Resolução n. ${ }^{\circ} 01$ de 20 de fevereiro de 2003 da Secretaria Municipal de Educação de Marabá/PA, assim como previsto no Art. 26 da Lei de Diretrizes e Bases da Educação (LDB) n 9394/96.

Os professores que ministram essa disciplina costumam ter formação diversificada. Possuem licenciatura em áreas diversas, como Geografia, História, Pedagogia, entre outras, o que faz com que, em muitos casos, a formação do professor seja indiferente para lecionar a disciplina.

Em nossa investigação, estudamos a fundamentação legal da disciplina e percepção dos professores e sua contribuição para o ensino da disciplina de Estudos Amazônicos, no município de Marabá-PA.

Este artigo está dividido em seis seções. Introdução onde citamos a criação da disciplina de Estudos Amazônicos e explicitamos o que é tratado nas outras seções, $\mathrm{Na}$ segunda seção, "Por que estudar a Amazônia?", comentamos a lei que cria a disciplina a nível municipal e discorre sobre o currículo, matriz curricular, problemáticas a respeito da formação do professor e interdisciplinaridade. Na terceira seção, intitulada "O perceber e o ato de ensinar", elencamos alguns conceitos de Merleau-Ponty e Masini. Na quarta seção, "O perceber e o professor", procuramos entender o papel do professor e o perceber. Na quinta seção, "O perceber e o aluno", buscamos exemplificar o papel do aluno e sua percepção no meio ambiente do espaço vivido, elucidamos a percepção através do tato e por meio da compreensão do pensamento de Brun. Na conclusão explicamos como chegamos aos questionamentos propostos. E finalizamos com a apresentação de uma lista das referências utilizadas.

\section{Por que estudar a Amazônia?}

O currículo escolar dos ensinos fundamental e médio é composto por dois eixos, o da Base Nacional Comum Curricular (BNCC) e a Parte Diversificada (PD). O BNCC é obrigatório em âmbito nacional e as disciplinas são fixadas pelo Conselho Federal de Educação. A PD do currículo é composta de disciplinas que serão escolhidas com base em relação elaborada pelos Conselhos de Educação, para os respectivos sistemas de ensino.

A Lei n ${ }^{\circ}$ 12.796, de 4 de abril de 2013 que altera o Art. 26 da LDB de 1996 diz que:

\footnotetext{
Os currículos da educação infantil, do ensino fundamental e do ensino médio devem ter base nacional comum, a ser complementada, em cada sistema de ensino e em cada estabelecimento escolar, por uma parte diversificada, exigida pelas características regionais e locais da sociedade, da cultura, da economia e dos educandos.
}

É necessário entender a proposta da parte diversificada analisando os variados conceitos de currículo existentes. A palavra currículo vem da palavra latina scurrere (correr) e refere-se a curso (ou carro de corrida), o que leva etimologicamente a uma definição de currículo como um curso a ser seguido, ou mais especificamente, apresentado (GOODSON, 1995).

O Conselho Nacional de Educação deixa bem claro referente de como deve ser elaborada a Parte Diversificada a partir da LDB de 1996: 
A lei n. 9.394/96 das diretrizes e bases da educação nacional contém mudanças significativas com relação ao ordenamento educacional anterior. A nova lei em seu art., 92, chega mesmo a revogar as leis de educação precedente. Isto significa mais do que a instituição de uma outra lei. Significa um projeto que contenha uma mudança significativa, nova. Esta novidade atende na lei n. 9.394/96 pelo nome de autonomia [...] (BRASIL, 2006).

Apple (2006) afirma que "o currículo nunca é um conjunto neutro de conhecimentos, ele é parte de uma tradição seletiva, resultado da seleção de alguém, da visão de algum grupo acerca do que seja conhecimento legítimo." Sendo assim, podemos entender o currículo como a base cultural de determinado grupo social, em diversas temporalidades, entrelaçando-se entre o tradicional e o moderno.

A Secretária de Estado e Educação do Pará define o currículo como:

O currículo deve ser definido a partir das necessidades específicas de cada realidade escolar, por todos os sujeitos envolvidos no contexto em questão. Isto implica dizer que na definição do currículo deve-se partir da "realidade", da "necessidade" dos alunos para a seleção dos "saberes" e "conhecimentos" a serem por eles apropriados. (PARÁ, 2003).

Nesse contexto, o currículo deve atender as especificidades de cada comunidade escolar, partindo de uma escala local ao global. A importância dos grupos sociais e de suas culturas necessitam ser compreendidas para que haja uma valorização da cultura local em detrimento ao movimento de aculturação que permeia a sociedade globalizada. Porém, muito além de um currículo que vise apenas atender necessidades, devemos almejar um currículo crítico-libertador.

\footnotetext{
Não reduzimos, por isso mesmo, sua compreensão, a do currículo explícito, a uma pura relação de conteúdos programáticos. Na verdade, a compreensão do currículo abarca a vida mesma da escola, o que nela se faz ou não se faz, as relações entre todos e todas as que fazem a escola. Abarca a força da ideologia e sua representação não só enquanto idéias, mas como prática concreta. No currículo oculto o "discurso do corpo", as feições do rosto, os gestos, são mais fortes do que a oralidade. A prática autoritária concreta põe por terra o discurso democrático dito e redito. (FREIRE, 2000, p. 123).
}

O estado do Pará em sua proposta curricular de 2003, elencou alguns critérios para que os estabelecimentos de ensino escolhessem disciplinas da parte diversificada. Nesta proposta surge a disciplina ${ }^{1}$ de Estudos Amazônicos cujo profissional habilitado para lecioná-la seriam os que possuíssem licenciatura plena em História, Geografia ou Ciências Sociais.

Baseando-se na proposta curricular que cria a disciplina de Estudos Amazônicos a nível estadual, a Prefeitura Municipal de Marabá publica a Resolução n ${ }^{\circ} 01$ de 20 de fevereiro de 2003, normatizada pelo Conselho Municipal de Educação, que estabelece a disciplina de Estudos Amazônicos na grade de disciplinas da proposta curricular do munícipio de Marabá, no estado do Pará.

A disciplina foi criada com intuito de atender as especificidades regionais, locais, aspectos relacionados a cultura e economia dos discentes. Porém, ao ser criada, não são estabelecidos critérios para escolha do professor habilitado para lecionar a disciplina. Professores com licenciatura em História e Geografia costumam ser os mais lotados pela Secretaria Municipal de Educação de Marabá (SEMED) para ministrar a disciplina. 
A proposta curricular de 2003 da disciplina, elaborada pela SEMED, trata da finalidade da disciplina que deve, entre outras coisas, levar o aluno a:

[...] conhecer e compreender o espaço amazônico a partir da perspectiva regional, ou seja, o processo de ocupação/integração da Amazônia ao mercado nacional e global, analisando e refletindo sobre suas múltiplas interrelações; contribuído assim para a construção de cidadãos conscientes, aptos a decidir e a atuar na realidade sócio-ambiental em que vive, de modo comprometido com a vida, com o bem-estar de cada um e da sociedade em escala local e global. Para isso é necessário desmistificamos mitos e preconceitos interligados em nossas mentes, mais do que isto: propormos a trabalhar com atitudes, com formação de valores, com o ensino e a aprendizagem de habilidades e procedimentos.

Mediante disto, é incompreensível conceber somente aos professores de História e Geografia a lidarem com uma temática tão abrangente, como se tais estivessem aptos a assumirem única e somente a responsabilidade de ministrar a disciplina. Assim, podemos compreender a afirmação de Vilson Leffa (2011, p.21) "O grande paradoxo da educação pública brasileira no ensino fundamental e médio é que o professor ensina ao aluno algo que ele mesmo não conhece".

Com a preferência dos professores de História e Geografia, observar-se uma polarização da disciplina de Estudos Amazônicos, acarretando como complementação daquilo que não foi possível ser trabalhado como matéria ${ }^{2}$ em História e Geografia, distanciando-se da real proposta da parte diversificada que almeja estabelecer uma conexão com os aspectos regionais e locais da sociedade, da cultura, da economia dos educandos, havendo então, a interdisciplinaridade.

Pontuschka (2009), define a interdisciplinaridade na escola como possibilidade de interação entre outras áreas do conhecimento, mas reconhece que existem dificuldades. "Pensar e agir interdisciplinaridade não é fácil, pois passar de um trabalho individual e solitário, no interior de uma disciplina escolar, para um trabalho coletivo faz emergirem as diferenças e as contradições do espaço social que é a escola". (PONTUSCHKA, 2009, p. 149).

Fazenda (2008) afirma que as discussões sobre a temática interdisciplinar surgiram na Europa, mais especificamente na França e, posteriormente, na Itália, no início década de 1960, num período de debates e embates políticos proporcionados pelos movimentos estudantis que reivindicavam, principalmente, um ensino mais sincronizado com as demandas de ordem social, política e econômica da época. Mediante o acontecido, o ensino de forma interdisciplinar teria sido uma resposta ao que os estudantes tanto reivindicavam, na medida em que os problemas sociais não poderiam ser resolvidos por uma única disciplina ou área do saber, pregava-se a interdisciplinaridade como uma possível saída para os problemas em questão.

Entretanto, a bipolarização no ensino de Estudos Amazônicos é fato primordial para que os professores formados em determinadas áreas do conhecimento, ensinem somente aquilo que foi aprendido durante sua formação, sem percorrer caminhos interdisciplinares.

Almeida (2013) traz pontos de reflexão fundamentais para compreendermos o estreitamento criado entre a disciplina de Estudos Amazônicos e sua relação com a Geografia, uma vez que destaca que a primeira é parte da matriz curricular obrigatória das escolas da rede municipal de ensino de Marabá, desde 2003, e que tem dentre suas finalidades a compreensão do espaço amazônico, pensando suas dinâmicas de ocupação, organização e reorganização, em escala local e global, chama a atenção, bem como, para a desconstrução de conceitos preconcebidos sobre a região, valorização do 
multicultural, da biodiversidade e a construção de valores individuais e coletivos. Elementos que parecem caminhar na perspectiva da prática da cidadania.

Foi somente no final da década de 90 que a disciplina Estudos Amazônicos se torna obrigatória nos currículos escolares do Ensino Fundamental II.

\begin{abstract}
Em Ofício encaminhado para as escolas públicas do Estado do Pará a diretora de Ensino deste estado Violeta Refkalefsky Loureiro encaminha as novas matrizes curriculares para o Ensino Fundamental e Médio para o ano de 1999, no qual faz uma alteração na parte diversificada do currículo com a inclusão da disciplina Estudos Amazônicos em substituição a disciplina Estudos Paraenses, com duas aulas semanais na $5^{\mathrm{a}}$ e $6^{\mathrm{a}}$ séries e três aulas semanais na $7^{\mathrm{a}}$ e $8^{\mathrm{a}}$ séries, tendo a seguinte justificativa "pela imperiosa necessidade da escola contribuir para a formação de uma consciência nos cidadãos sobre a Amazônia como uma questão nacional e ser a Amazônia o maior e mais rico sistema natural do planeta Terra". (ALVES, 2016. p. 9).
\end{abstract}

Silva (2014) comenta que tal disciplina é também componente curricular obrigatório do ensino fundamental no Município de Belém, como determinado pela SEDUC-PA e aprovado pelo Conselho Estadual de Educação, em documento de 1996. Em seu trabalho, a autora analisa a disciplina de Estudos Amazônicos no contexto da disciplina de História, mostrando que a História Regional é importante e que, de acordo com os conteúdos indicados pela SEDUC-PA, a História da região deve ser compreendida a partir de um olhar externo, como diz a pesquisadora:

Deixa-se assim de explorar estudos importantes sobre a participação indígena e negra no contexto da sociedade da região, como sujeitos sociais participantes do processo histórico e de formação da identidade cultural, fundamentados pelo respeito às diferenças étnicas, ambientais, religiosas, linguísticas dentre outras.

É de fundamental importância os estudos históricos e das ciências geográficas para compreensão da Amazônia. Porém, talvez seja necessário criar uma identidade própria para a disciplina e não apenas entendê-la como complementação de outras áreas de ensino.

\title{
$O$ perceber e o ato de ensinar
}

Segundo Masini (2003, p. 39), “Compreender as especificidades e singularidades perceptuais na existência humana requer uma complexidade de conhecimentos. O ponto de partida para essa compreensão é a abertura do ser humano ao que circunda". Partindo desse pressuposto, faz-se necessário entender qual o papel do professor no ato de ensinar. Ensinar uma disciplina, que talvez não tenha identidade, porém o seu nome, Estudos Amazônicos, leva o imaginário, seja do professor ou do aluno, a criar estreitas relações com ambiente em que vive.

$\mathrm{O}$ ato de ensinar, fundamentado na ação docente, vai além do que apenas transmitir conhecimentos, é fator primordial para que sejam estabelecidas relações humanas com pessoas capazes de iniciativa e uma certa capacidade de resistir ou de envolver-se na ação dos docentes. Com os professores de Estudos Amazônicos não é diferente, entretanto, muito mais do que um processo de ensino/aprendizagem, ensinar a disciplina de Estudos Amazônicos na região amazônica, é um ato de cidadania.

Neste ponto da pesquisa, é necessário desmembrar o professor e o aluno do espaço amazônico, para que possamos elucidar qual o papel dos sujeitos para a construção de um pensamento coletivo e preservacionista do meio ambiente amazônico. 


\section{O perceber e o professor}

O papel do professor de Estudos Amazônicos é extremamente importante para continuidade da floresta Amazônica.

Um professor de profissão não é somente alguém que aplica conhecimentos produzidos por outros, não é somente um agente determinado por mecanismos sociais: é um ator no sentido forte do termo, isto é, um sujeito que possui conhecimentos e um saber-fazer provenientes de sua própria atividade e a partir dos quais ele a estrutura e a orienta. (TARDIF, 2002, p. 230).

Partindo deste pressuposto, Tardif, 2014, faz questão de abordar o conhecimento adquirido por suas relações, onde o autor coloca três saberes, os saberes disciplinares, os saberes curriculares e os saberes experienciais. Como diz Tardif (2014, p. 39):

Essas múltiplas articulações entre a prática docente e os saberes fazem os professores um grupo social e profissional cuja existência depende, em grande parte, de sua capacidade de dominar, integrar e mobilizar tais saberes enquanto condições para sua prática.

Dada essa importância ao professor de Estudos Amazônicos, cabe a ele, instrumentar sua prática ao cotidiano do espaço amazônico, fazendo com que haja um estreitamento entre o espaço vivido e o espaço pensado ${ }^{3}$.

Segundo Vygotsky (1991), a mente humana reflete primordialmente na prática pedagógica, considerando o desenvolvimento da inteligência e da cognição como um processo ligado ao desenvolvimento social, fruto da interação social. Vygotsky destaca um ser humano capaz de criar suas próprias condições de existência.

É o mesmo homem que Paulo Freire apresenta, um ser que não existe sozinho, mas que existe nos e pelos outros, que é capaz de mudar a sua história e a história do mundo. É o mesmo homem que Milton Santos destaca, aquele que, ao agarrar-se ao seu lugar, para não se perder num mundo globalizado tão perversamente que não lhe dá chances de se humanizar. É no lugar e no cotidiano que o homem se percebe como sujeito.

Neste sentido, busca-se um professor de Estudos Amazônicos que entenda o seu papel no lugar vivido, para que através deste professor, seja construído um pensamento preservacionista da floresta amazônica e partindo desse pensamento preservacionista, possamos agregar sentimentos entre os sujeitos e a floresta. Cremos assim, que podemos iniciar um novo processo de como ensinar conteúdos referentes à Amazônia.

\section{$O$ perceber e o aluno}

Como propomos na seção três, elucidamos o papel do professor no ensino da disciplina de Estudos Amazônicos e agora dissertaremos sobre a função do aluno enquanto ser construtor do conhecimento.

O aluno do Ensino Fundamental de $6^{\circ}$ ao $9^{\circ}$ ano, cuja faixa etária média é de 11 a 15 anos, talvez esteja mais insensível ao se perceber em relação ao espaço social vivido. Entretanto, este adolescente, tratado como insensível, é capaz de se envolver com as dinâmicas sociais do espaço vivido, de maneira melhor e mais atuante do que muitos adultos. 
Como exemplo desta sensibilidade da qual tratamos podemos dizer que, no ano de 2013, foi desenvolvido pelo autor deste texto na Escola Municipal de Ensino Fundamental (EMEF) Rio Tocantins, localizada na cidade de Marabá, estado do Pará, um projeto intitulado "CAIC, por que te quero verde?". O projeto consistia na arborização da escola e gerou muitas expectativas nos alunos e professores envolvidos.

Através deste projeto houve um envolvimento considerável dos alunos com o meio ambiente amazônico, fazendo com que fossem estimulados a criar entre eles um pensamento coletivo preservacionista, criando assim, um sentimento compreensivo da importância da floresta para sobrevivência do povo que vive nela e fora dela.

Com a plantação das primeiras mudas na escola Rio Tocantins, o projeto também incluía que cada aluno participante desse nome à árvore plantada e cuidasse dela até o fim de sua permanência na escola, transferindo a responsabilidade e cuidados com a árvore para um aluno mais novo na escola. Cada árvore recebia uma espécie de certidão de nascimento, constando a data em que foi plantada e os alunos que cuidaram dela.

O projeto de arborização da escola visava além do paisagismo, um futuro sombreamento e um maior contato dos alunos com a natureza criando assim, um sentimento mútuo, em professores, alunos e comunidade, de preservação da floresta. Outro estágio do projeto seria estender a plantação de árvores no entorno da escola e nos terrenos da comunidade escolar.

O projeto "CAIC, por que ti quero verde?" continuou na escola e fez o pesquisador refletir sobre a importância do uso dos vários sentidos para contemplação e preservação da natureza o que, no caso do tato, nos remete ao pensamento de Brun (1991, p. 173), "O tocar possui, com efeito, uma seriedade de que a visão e impossibilitada, pois se a visão nos dá um imediato pensado, a mão dá-nos um imediato vivido através de todas as peripécias que foram necessárias para chegar até ele".

O pensamento de Brun é essencial para que o estudo da percepção fosse ampliado no contexto desta pesquisa, não se atendo apenas ao campo do visível, explorando outros sentidos extremamente necessários para perceber o sujeito no meio ambiente amazônico.

Foi necessária a menção do projeto "CAIC, por que ti quero verde?", nesta pesquisa, para entendermos o quanto o aluno, através de um projeto de arborização de uma escola, pode interagir com os seus diversos sentidos e sentir-se parte do contexto amazônico para conservação e uso adequado dos seus recursos.

\section{Conclusão}

Entendemos, que a partir da fundamentação legal da disciplina de Estudos Amazônicos através do Art. 26 da LDB n 9394/96, que trata sobre a PD e da normativa de 2003 do Conselho Municipal de Educação de Marabá, a disciplina tornou-se um campo a ser explorado e, devido às poucas pesquisas realizadas sobre isto, a formação do professor torna-se essencial para que a Amazônia seja entendida, não apenas como uma região a ser explorada, mas como um espaço a ser preservado e os seus recursos serem utilizados primeiramente em prol dos que vivem nela, para depois satisfazer a necessidade, ou saciedade, de outras regiões do Brasil e países do mundo.

Este artigo buscou entender o papel do professor e do aluno na construção de um pensamento coletivo preservacionista, elencando conceitos usados por Merleau-Ponty, Masini, Vygotsky, Brun a respeito do sujeito no próprio mundo e suas relações com o outro e a natureza. 
Como este artigo faz parte da construção de nossa dissertação de mestrado, pretendemos posteriormente, na coleta dos dados, aplicar os conceitos em questão e entender questões como o que de fato pensa o professor de Estudos Amazônicos a respeito de ensinar a disciplina no ambiente amazônico, qual a percepção desse professor, qual a percepção do aluno e qual a importância desses sujeitos na preservação da Amazônia.

Por fim, vale ressaltar que a partir da legislação educacional e da matriz curricular da SEDUC/PA do ano de 2003, e dos documentos envidados pela SEMED e pelo Conselho Municipal de Educação-CME, constatamos que a ausência de avaliação para selecionar o profissional que trabalha no município de Marabá, se dá pela interpretação dada às normativas criadas após a municipalização do Ensino Fundamental. Cabe realçar, também, que não existe um espaço específico para formação continuada de Estudos Amazônicos, sendo está atrelada a formação continuada de Geografia, o que reitera nosso argumento de continuidade da "geografização" da disciplina no município de Marabá.

\section{Notas}

1 - Segundo Piletti (1994), a disciplina é um conjunto sistemático e especializado de conhecimentos, resultante da evolução cultural da humanidade.

2 - Segundo Pilleti (1994), matéria é todo o conjunto de conhecimentos, entretanto esses conhecimentos podem ser apresentados de diversas formas.

3 - A ciência geográfica, definida pelo viés do espaço vivido, não tenta criar leis nem observar regularidades generalizadoras. Seu ponto de partida é, ao contrário, a singularidade e a individualidade dos espaços estudados. Ela também não procura avançar resultados prospectivos e normativos, como as ciências ditas racionalistas. Seu objetivo principal é fornecer um quadro interpretativo às realidades vividas espacialmente. A objetividade não provém de regras estritas de observação, mas do uso possível das diversas interpretações na compreensão do comportamento social dos atores no espaço. Por seu contato e por sua participação direta no conjunto de significações criadas em uma comunidade espacial, o geógrafo torna-se um personagem ativo no próprio desenvolvimento desta comunidade. Contudo, ele deve ter a consciência explícita de seu engajamento pessoal e, portanto, da impossibilidade de um distanciamento 'objetivo' com relação ao seu campo de pesquisa. (GOMES, 1996, p. 320).

\section{Referências}

ALMEIDA, D.V. A disciplina intitulada estudos amazônicos constituindo-se como mais um espaço para o conhecimento geográfico em sala de aula. In: Encuentro de Geógrafos de América Latina. Anales del XIV EGAL. Lima: Unión Geográfica Internacional, 2013. p. 1-13.

ALVES, D.H.R. Ciclo x Período: A disciplina "Estudos Amazônicos" entre duas propostas curriculares. In: Simpósio Eletrônico Internacional de Ensino de História. União da Vitória - PR, 2016. p. 7-11.

APPLE, Michael W. Ideologia e currículo; tradução FIGUEIRA, Vinicius. $3^{\mathrm{a}}$ ed. Porto Alegre: Artmed, 2006.

BRASIL. Ministério da Educação e Cultura. (2002). Resolução CNE/CP no 1/2002, de 18 de fevereiro. Diretrizes Curriculares Nacionais para a Formação de Professores da

Educação Básica, em nível superior, curso de Licenciatura, de graduação plena. 
Ministério da Educação e Cultura. (2001). Parecer CNE/CP no 492/2001, de

03 de abril. Diretrizes Curriculares Nacionais dos Cursos de História, Filosofia, Geografia, Serviço Social, Letras, Biblioteconomia, Arquivologia e Museologia.

Secretaria de Educação Fundamental. Parâmetros curriculares nacionais: geografia / Secretaria de Educação Fundamental. Brasília: MEC/SEF, 1998.

. Secretaria de Educação Fundamental. Parâmetros curriculares nacionais: história / Secretaria de Educação Fundamental. Brasília: MEC/SEF, 1998.

. Ministério da Educação. Lei de Diretrizes e Bases da Educação Nacional. no 9394. Brasília; MEC, 1996.

BRUN, Jean. A mão e o espírito. Rio de Janeiro: Edições 70 Ltda, 1991.

FREIRE, P. A educação na cidade. $4^{a}$ ed. São Paulo: Cortez, 2000.

FAZENDA, I.C.A. Interdisciplinaridade: História, teoria e pesquisa. $13^{\text {a }}$ ed. São Paulo: Papirus, 2008. (Coleção Magistério: Formação e Trabalho Pedagógico).

GOODSON, I. F. História do currículo, profissionalização e organização social do conhecimento: paradigma para a história da educação. In: GOODSON, I. F. (Org). Currículo: Teoria e História. Petrópolis: Vozes, 1995, p. 116-140.

GIL, A.C. Como elaborar projetos de pesquisa. 4. ed. São Paulo: Atlas, 2008.

ISTSCHUK, M.E.; ROSSO, A. J. Parte diversificada do currículo: análise das propostas para a Física nos Campos Gerais. In: V Encontro Nacional de Pesquisa em Educação em Ciências. V ENPEC - Caderno de Resumos. Bauru: ABRAPEC, 2005. v. 05. p. 412-412.

LEFFA, J.V Criação de bodes, carnavalização e cumplicidade: considerações sobre o fracasso da LE na escola pública. In: LIMA, D. C. (Org.). Inglês em escolas públicas não funciona? Uma questão, múltiplos olhares. São Paulo: Parábola, 2011.

MASINI, E.F.S. A Experiência perceptiva é o solo do conhecimento de pessoas com e sem deficiências sensoriais. Psicologia em estudo. Revista da Universidade Federal de Maringá, v. 8, n. 1. 2003. p. 39-43.

MERLEAU-PONTY, M. Fenomenologia da percepção. 2 ed. São Paulo: Martins Fontes, 1999 (Tópicos).

PARÁ. Secretaria Executiva de Educação. Proposta curricular 2003: ensino médio/ Secretária Executiva de Educação. Belém: SEDUC, 2003.

PONTUSCHKA, Nídia Nacib; PAGANELLI, Tomoko Iyda; CACETE, Núria Hanglei. Para ensinar e aprender Geografia. 3.ed. São Paulo: Cortez, 2009. p. 141-169. 
PREFEITURA MUNICIPAL DE MARABÁ. Resolução Número 01 de 20 de fevereiro de 2003. Marabá/PA: Secretaria Municipal de Educação - SEMED. Conselho Municipal de Educação, 2003.

- Proposta Curricular: Os múltiplos olhares sobre os caminhos da aprendizagem. Marabá/PA: Secretaria Municipal de Educação - SEMED. Diretoria de Ensino. Ensino Fundamental, 2006.

TARDIF, M. Saberes docentes e formação profissional. Tradução de Francisco Pereira.

Petrópolis: Vozes, 2002.

TARDIF, M. Saberes docentes e formação profissional. In: TARDIF, M. (Org). os professores enquanto sujeitos do conhecimento. 17 $7^{\text {a }}$ ed. Rio de Janeiro: Vozes, 2014. p. 227-244.

VYGOTSKY, L. S. A formação social da mente. $4^{\text {a }}$ edi. São Paulo: Martins Fontes, 1991. 